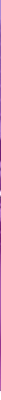

\title{
AÇÕES DE PROMOÇÃO DA SAÚDE EM CRIANÇAS MENORES DE UM ANO
}

\author{
HEALTH PROMOTION ACTIONS ON CHILDREN UNDER ONE YEAR
}

\begin{abstract}
Carla Taiza Pereira Cordeiro, Cibelle Bezerra Freitas, Edjania Novais da Silva, Maria Rosiane Alves dos Santos, Maria Suzana da Silva, Mônica Maria Viana, Paula Arícia de Sousa Alencar, Tamyres Pereira da Silva, Ana Paula Ribeiro de Castro, Katia Monaisa Figueiredo Medeiros
\end{abstract}

Centro Universitário Doutor Leão Sampaio - UNILEÃO Av. Leão Sampaio km 3 - Lagoa Seca Juazeiro do Norte, Ceará, Brasil E-mail:anacastro@leaosampaio.edu.br; katiafigueiredo@leaosampaio.edu.br

\section{RESUMO}

A fase do nascimento até o primeiro ano de vida de uma criança é caracterizada como uma das fases de muitas mudanças, dúvidas e descobertas tanto para a mesma quanto para seus responsáveis. Nesse sentido, o profissional enfermeiro tem papel importante durante a consulta de puericultura para esclarecimento de dúvidas. Objetivou-se com este estudo promover ações de saúde voltadas a crianças menores de 1 ano. Desse modo, foram desenvolvidas intervenções, as quais que consistiram em uma proposta de ação construída a partir da identificação de problemas, necessidades ou mesmo fatores determinantes. Contou-se com o público mínimo de pessoas, ao longo das intervenções e durante as mesmas alguns participantes interagiram, reconheceram aspectos relacionados à melhoria da saúde e opinaram sobre as temáticas apresentadas. Com base no que foi apresentado no desenvolvimento deste estudo, observou-se que ainda há muito a se fazer na prática de prevenção e promoção da saúde da população alvo do mesmo.

Palavras-Chave: Cuidado Infantil; Puericultura; Educação em Saúde.

\section{ABSTRACT}

The phase of birth to the first year of a child's life is characterized as one of the phases of many changes, doubts and discoveries for both the same and for those responsible. In this sense, the nurse professional plays an important role during the child care consultation to clarify doubts. The objective of this study was to promote health actions aimed at children ultin 1 year old. In this way, interventions were developed, which consisted in a proposal of action built from the identification of problems, needs or even determinant factors. There was a minimum audience of people throughout the interventions, during which some participants interacted, acknowledged aspects related to the improvement of health and opined on the themes presented. Based on what was presented in the development of this study, it was observed that there is still much to be done in the practice of prevention and health promotion of the target population.

Keywords: Child Care; Childcare; Health education. 


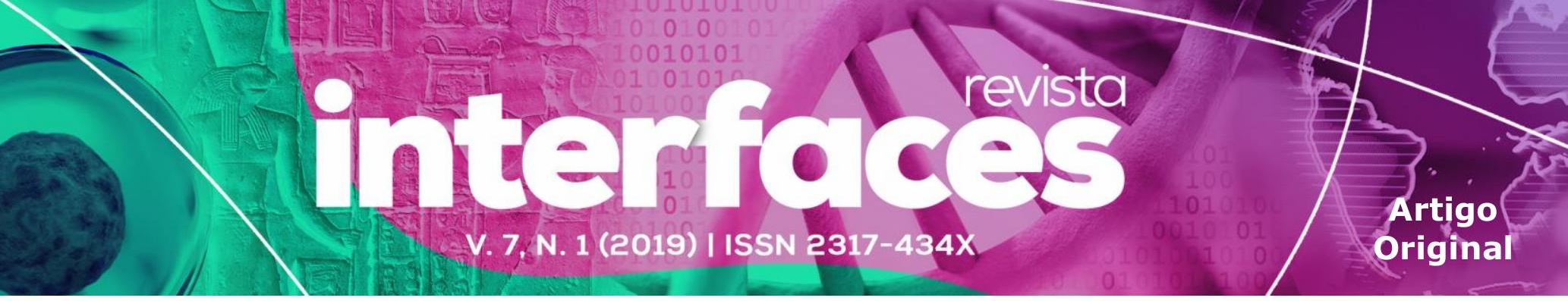

As ações planejadas e executadas pelos profissionais de saúde da Equipe de Saúde da Família (ESF) voltadas à saúde da criança revelam-se com

\section{INTRODUÇÃO}

Nos primeiros anos de vida da criança, o desenvolvimento infantil caracteriza-se por um período de formação do sujeito e de suas potencialidades humanas. Entretanto, alguns distúrbios que podem ocorrer nessa fase são responsáveis por consequências graves para o indivíduo. Nesse ponto, é de grande relevância ações que visem promover a saúde e que venham a garantir e manter a qualidade de vida das crianças (BRASIL, 2009)

No ano de 1998, o Ministério da Saúde, por meio da Secretária de Políticas de Saúde criou o projeto Promoção da Saúde, objetivando promover a qualidade de vida das pessoas, das famílias e das comunidades, visando ainda diminuir a vulnerabilidade e riscos à saúde relacionados aos seus determinantes e condicionantes (BRASIL, 2006).

$\mathrm{Na}$ avaliação integral à saúde da criança, realiza-se o acompanhamento do crescimento e o do desenvolvimento, incluindo ações de promoção à saúde, de hábitos de vida saudáveis, vacinação, prevenção de problemas, agravos à saúde e cuidados oportunos (BRASIL, 2009).

Esse acompanhamento é ser realizado, por meio da consulta de puericultura, sendo esta fundamental e com influência positiva no crescimento e desenvolvimento, assistindo a criança de forma integral, limitando-se não somente ao exame físico como peso, medidas antropométricas e vacinação, mas proporcionando um acolhimento humanizado tanto das crianças como dos pais e/ou cuidadores durante o atendimento. Neste sentido, durante a puericultura são oferecidas orientações frente à saúde da criança para que esta possa crescer e se desenvolver de maneira saudável, prevenindo agravos à saúde, possibilitando ainda que os responsáveis possam revelar suas dúvidas e anseios (VIEIRA et al., 2012)

O profissional enfermeiro tem papel importante durante a consulta de puericultura, utilizando este momento como uma ferramenta oportuna para realizar ações de educação em saúde, as quais podem ser feitas em grupos ou mesmo de forma individual, enfatizando várias temáticas e ao mesmo tempo fazendo o acompanhamento integral (VASCONCELOS et al., 2010). respostas positivas, entretanto desafios são enfrentados como, por exemplo, a compreensão dos pais e responsáveis da importância desse momento de consultas e de diálogo. Ressalta-se ainda que a assiduidade dos responsáveis no acompanhamento dos seus filhos deve ser incentivado e estimulado para que seja contínuo (BENÍCIO et al., 2016).

Nesse sentido, para que a criança tenha um bom desenvolvimento e cresça de maneira saudável, estando preparada para enfrentar as transformações que ocorrem em seu organismo, é essencial que cuidados específicos sejam ofertados, desse modo a promoção e recuperação da saúde da criança é prioridade à saúde infantil (VASCONCELOS et al., 2010).

Mediante ao que foi exposto apresenta-se o seguinte questionamento: Qual a importância das ações de saúdes voltadas as crianças menores de um ano?

A temática foi escolhida em virtude de já existir o projeto realizado na Unidade de Saúde e as acadêmicas apresentarem o interesse de trabalhar com os responsáveis e cuidadores das crianças na faixa etária menor de um ano de vida, incentivando o cuidado e hábitos de vida saudável.

O desenvolvimento do projeto é relevante, pois foram selecionados assuntos essenciais para que, por meio de ações educativas, os pais e cuidadores de crianças fossem orientados e esclarecidos, buscando contribuir para cuidados na infância.

O projeto trouxe contribuições como a troca de conhecimento entre as acadêmicas e o público alvo, bem como a compreensão da necessidade e importância de trabalhar ações educativas como forma de proporcionar melhorias nas condições de saúde não somente da criança, mas de toda a família.

\section{METODOLOGIA}

Trata-se de uma ação de extensão de natureza descritiva exploratória buscando promover ações de intervenção em crianças menores de 01 ano de idade.

Oliveira et al., (2003) ressaltam que o desenvolvimento de uma ação consiste em traçar um caminho eficaz que conduzirá a um fim desejado. Neste sentido, preocupa-se com fatores como embasamento teórico, situação-problema, hipóteses, dentre outros. $\mathrm{Na}$ elaboração do projeto, não se pode afirmar que existam 


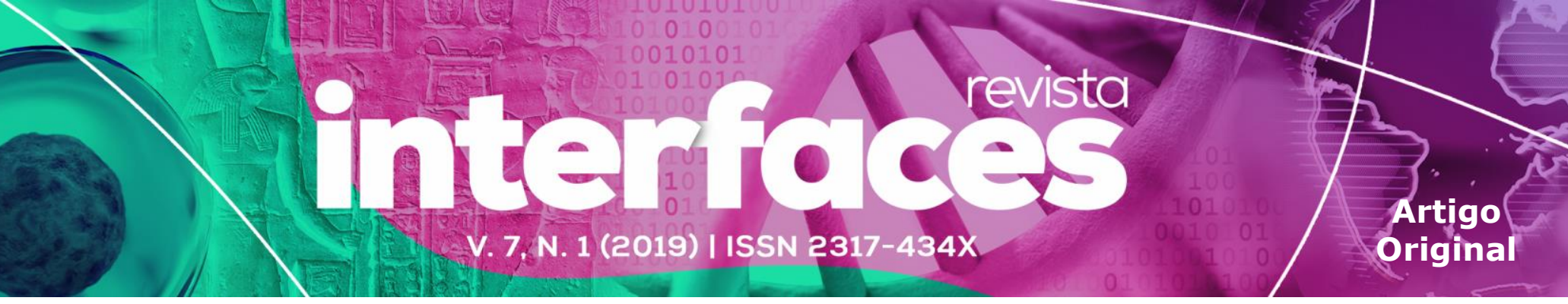

regras preestabelecidas, pois tudo dependerá do assunto proposto.

A ação desenvolvida foi de intervenção que conforme Silva e Brandão (2003) consiste em uma proposta de ação construída a partir da identificação de problemas, necessidades ou mesmo fatores determinantes. O termo projeto refere-se a um plano objetivando a realização de uma ação coordenada no futuro. A palavra intervenção está voltada a uma ação objetiva, um fazer concreto numa dada realidade.

A ação de intervenção intitulada Ações de promoção a saúde voltadas as crianças menores de um ano, foi desenvolvido com um grupo de pais e/ou responsáveis por crianças na faixa etária menor de um ano, em uma Unidade Básica de Saúde, localizada em Juazeiro do Norte -CE, no primeiro semestre de 2019. A temática foi definida a partir da observação nos atendimentos de puericultura, onde se percebeu dificuldades dos responsáveis em realizar alguns cuidados simples, mas de grande relevância contribuindo assim para o crescimento e desenvolvimento da criança saudável.

No primeiro mês realizou-se um planejamento onde foram escolhidos temas, as datas das intervenções e os materiais que deveriam ser utilizados para desenvolver as ações. Neste sentido, ocorreram quatro ações com as seguintes temáticas: aleitamento materno, introdução de novos alimentos, higienização e prevenção de acidentes.

Os pais e/ou responsáveis eram informados durante os atendimentos sobre as ações e foram feitos convites impressos, neles continham a data da ação, o assunto e o horário. Com a ajuda dos Agentes Comunitários de Saúde, os convites foram distribuídos na comunidade. Em Para a realização das ações, utilizou-se recursos áudio visuais e em outros momentos rodas de conversas, onde se buscou deixar os convidados à vontade para expor suas dúvidas e anseios assim como para facilitar a troca de conhecimentos.

\section{REFERENCIAL TEÓRICO}

\section{PREVENÇÃO DE ACIDENTES EM CRIANÇAS MENORES DE 1 ANO}

O crescimento infantil, especialmente nos primeiros anos de vida, é uma fase que auxilia no desenvolvimento de um indivíduo e da sua capacidade humana. Porém alguns problemas poderão surgir durante essa fase que são causadores de graves impactos para o sujeito. A Atenção Primária em Saúde possibilita esse apoio à criança no Programa de Puericultura, tendo como objetivo promoção, prevenção, reconhecimento precoce e melhoria dos agravos à saúde (BENECIO et al,2016).

Entende-se como acidentes uma sequência de ocorrências não intencionais em um período curto, onde um agente externo causa instabilidade, provocando danos físicos, materiais e/ ou psicológicos. O acidente é um evento complicado que deve ser investigado, com particularidade, para investigação dos incidentes e fatores referente em cada caso, quanto de modo geral, pela verificação do cenário de riscos presentes em cada faixa etária ou até em grupos específicos (FILÓCOMO et al 2017).

Os menores são mais vulneráveis fisicamente, principiantes, não tem medo e ainda estão promovendo suas desenvolturas de reação aos perigos. É de suma importância adaptar os ambientes nos quais elas vivem (escola, casa, parquinhos, etc.) e orientar seus cuidadores para identificar as ameaças e terem uma inspeção ativa das crianças (BRASIL, 2014).

Compreender as singularidades e diferentes peculiaridades do desenvolvimento de uma criança sabe-se que é uma boa escolha para perceber a ocorrência de determinados acontecimentos neste contexto. Ao longo do tempo, as crianças passam a fortalecer suas habilidades motoras, cognitivas e sensoriais. Durante o tempo em que este curso não está completo, o sujeito é suscetível a uma série de perigos exigindo, portanto, cuidados especiais e atenção total (BRASIL, 2014)

\section{INTRODUÇÃO ALIMENTAR PARA CRIANÇAS MENORES DE UM ANO}

A Organização Mundial de Saúde recomenda que o aleitamento materno exclusivo (AME) seja oferecido até o sexto mês e a partir dessa idade, complementando o leito materno, sejam oferecidos outros líquidos e alimentos adequados à criança e sua idade, sob livre demanda até dois anos ou mais. (CAMPOS, et al, 2015)

A alimentação das crianças em seus primeiros anos é algo que dará respostas ao longo de sua vida, por isso sua adequação de forma correta previne inúmeras doenças que poderiam acometer este indivíduo, como diabetes mellitus tipo I, deficiência de vitaminas. (CRISTINA E ELSA, 2004). 


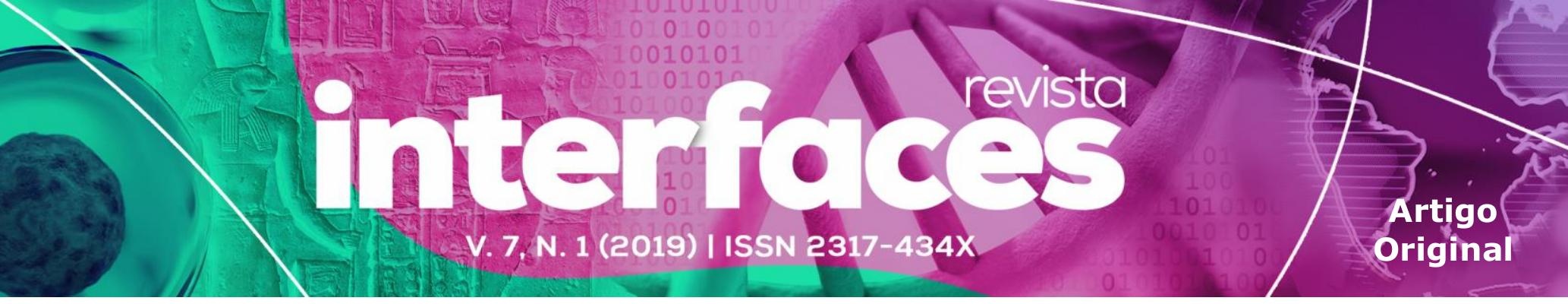

Após completar seis meses de vida a adição da alimentação complementar pode acontecer de forma gradativa suprindo as necessidades de energia, proteína, gordura, minerais, primordialmente o ferro, já que neste tempo as reservas hepáticas tendem a diminuir e se a mãe, que continua amamentando, não possui um bom aporte a suplementação deste deve acontecer e vitaminas A e C, sem contaminação, sem muitos condimentos ou sal e de fácil consumo e boa aceitação. (CRISTINA E ELSA, 2004).

Fuzeto e Oliveira, (2010) citam o Guia Alimentar de 2002 que orienta a introdução dos alimentos 3 vezes por dia se em aleitamento materno e 5 vezes se a criança já estiver desmamada. $\mathrm{O}$ autor relata que o prato deve ser colorido e variado e que açúcar, café, enlatados, refrigerante, balas, salgadinhos e outras guloseimas devem ser evitados nos primeiros anos de vida.

Cristina e Elsa (2004) complementam que para introduzir novos alimentos recomenda-se ser um de cada vez, a cada 3 a 7 dias e que sejam preparados exclusivamente para elas, sendo inicialmente semissólidos e macios. A partir dos oito meses, ela pode receber alimentos consumidos pela família, desde que amassados e desfiados. Aos 10 meses, a criança já deve estar recebendo alimentos granulosos e aos 12 já pode receber o mesmo que é oferecido à família.

Cristina e Elsa (2004) lembram que este é um momento de interação entre mãe ou cuidador e criança e que deve haver bastante paciência por ser uma rotina nova e uma relação amorosa durante a refeição.

\section{HIGIENIZAÇÃO CORPORAL INFANTIL}

Devido à imaturidade imunológica do sistema da criança, sobretudo no período de 0 á 1 ano de idade, necessita de um olhar atencioso para sua saúde, pois é inteiramente dependente do cuidado de seus responsáveis, sendo imprescindível considerar o saber da família e como cuida, especialmente quando se refere a crianças nessa faixa etária (ANDRADE et al., 2012).

Estudos relatam que o cuidar ineficiente no que se trata dos hábitos de higiene pode estar ligado com o adoecimento das crianças, como obtenção de enteroparasitoses, problemas dentários, escabiose e pediculose. Destaca-se que a qualidade do cuidado pode depender das habilidades do cuidador da criança, geralmente a mãe, e da particularidade em que esteja insertado. O empoderamento da mãe é essencial para realizar o cuidado qualificado para o menor, bem como promover a sua saúde por meio do compartilhamento das responsabilidades com os profissionais de saúde (ANDRADE et al., 2012).

Sabe-se que na maioria dos casos é predominante as mães apresentarem insegurança na prestação dos cuidados, sobretudo relacionados aos hábitos de higiene, como troca de fraldas e banho, ocasionada, eventualmente pela falta de orientação dos profissionais de saúde na rede de atenção à saúde. Assim, deve ser urgente que a mãe inicie a cuidar do seu filho desde o princípio, para que possa aprender algo que venha reduzir as dificuldades no cuidado adequado (FROTA et al, 2011).

Com relação à higiene corporal, na hora do banho é possível a mãe proporcionar carinho ao filho, provocando estímulos, observar reflexos da criança, bem como o olhar e o toque, pois no banho, quanto mais estimulação mais aumenta a interação do binômio mãefilho (FROTA et al., 2011).

\section{RESULTADOS}

No dia 28 de fevereiro 2019 foi programado para acontecer a primeira intervenção com o tema prevenção de acidentes em crianças menores de 1 ano. Foi organizado juntamente com a equipe do PSF, contamos principalmente com o auxílio dos Agentes Comunitários de Saúde para que durante suas visitas convidassem a comunidade a participar da ação em saúde. Foram preparados materiais didáticos como, slides e panfletos.

Em seguida foi preparado um lanche para que fosse servido ao término da palestra. $\mathrm{O}$ local escolhido para a execução foi a sala de educação em saúde do PSF, às 14 horas. Porém, não compareceu nenhum participante, esperamos até as 16:00 horas e encerramos a atividade.

A segunda intervenção aconteceu no dia 22 de março, às 14:00 horas, na UBS. Desta vez para assegurar que a comunidade participasse, confeccionamos convites temáticos, para instigar o interesse e para que não esquecessem a data e horário. Durante as consultas de puericultura fizemos o convite aos Pais e responsáveis, salientando-os dos benefícios e importância da presença dos mesmos nas intervenções de saúde, contamos também com os ACS para entrega desses convites em domicílio. O tema abordado foi introdução Alimentar, como surgiram várias dúvidas a 


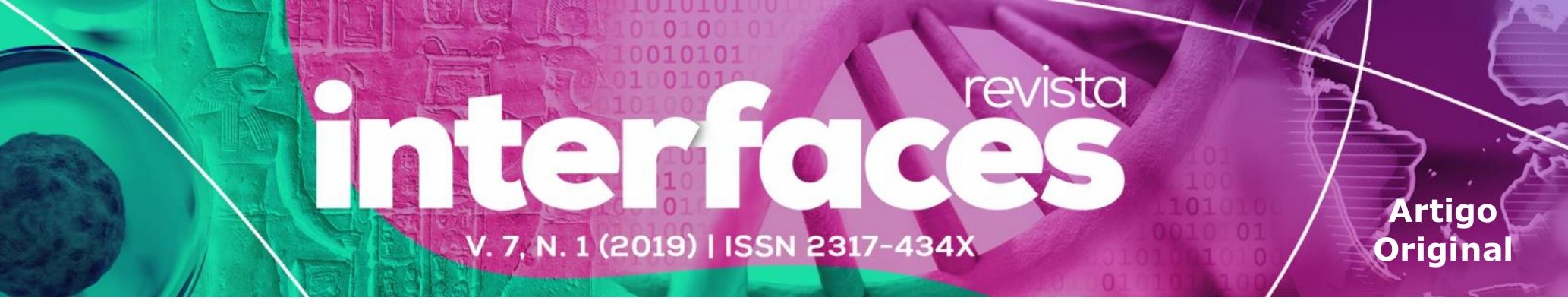

respeito do aleitamento materno, houve então a necessidade de compartilhar com o público esclarecimentos relacionados à amamentação, criandose assim uma nova ação.

No mesmo dia foi abordado o primeiro tema Prevenção de acidentes de crianças menores de 1 ano; aproveitando a presença de 4 pais e responsáveis que compareceram no dia.

O método usado foi uma roda de conversa, onde houve interação da equipe de estágio com os participantes. Ao final foi servido um lanche no qual foram fortalecidos os laços entre comunidade e equipe de saúde. Aproveitamos para convidá-los a participar da terceira intervenção.

A terceira ação realizou-se no dia 23 de março no qual foi abordado o tema higienização corporal infantil, compareceram 5 mães com seus bebês. Neste dia também realizamos uma roda de conversa, no qual foram tiradas dúvidas das mães e compartilhamos experiências. E assim finalizamos as intervenções direcionadas às crianças.

\section{CONCLUSÃO}

A educação em saúde constitui uma ferramenta importante, contribuindo para trazer mudanças e melhor qualidade de vida. Esse projeto teve como objetivo promover ações voltadas à criança menor de um ano. Foi possível orientar e esclarecer os pais e ou responsáveis sobre algumas temáticas como prevenção de acidentes, introdução alimentar, além de conscientizá-los sobre uma higienização adequada assuntos esses necessários para a saúde das crianças.

Observou-se que o público alvo tem dúvidas, carregam mitos e que apesar das orientações realizadas nas consultas, muito precisa ser trabalhado, principalmente a conscientização dos responsáveis da relevância de discutir assuntos voltados a saúde e bemestar da criança.

Com base no que foi apresentado no desenvolvimento deste trabalho, foi observado que ainda há muito a se fazer na prática de prevenção e promoção da saúde, uma vez que os pais desconhecem a importância das ações em saúde, apresentando dificuldades na realização da mesma pelo comparecimento de poucos responsáveis nas ações que foram desenvolvidas.

Contamos com o público mínimo de pessoas, ao longo da nossa apresentação alguns interagiram reconheceram e opinaram sobre as temáticas apresentadas. Como futuros profissionais da saúde, precisamos promover e intensificar a importância da ação em educação em saúde mostrando como algo esclarecedor e importante para seus usuários.

\section{REFERÊNCIAS}

ANDRADE Lucilande Cordeiro de Oliveira; SANTOS, Marcos Silva dos; AIRES, Julliana dos Santos; JOVETINO, Emanuella Silva; DODT, Regina Cláudia Melo; XIMENES, Lorena Barbosa. Conhecimento de puérperas internadas em um alojamento conjunto acerca da higiene do neonato. CogitareEnferm. 2012 jan/mar; 17(1):99-105. Disponível em:<

https://revistas.ufpr.br/cogitare/article/view/26381/17574> Acesso em 21 de fev. 2019.

BENICIO, et al. Cuidado à criança menor de um ano: perspectiva da atuação do enfermeiro na puericultura. Revenferm UFPE online, Recife, 10(2):576-84, fev., 2016. Disponívelem:https://periodicos.ufpe.br/revistas/revistaenfer magem/article/viewFile/10992/1 2345. Acessado em 23 de março de 2019.

BRASIL. Plano Nacional da Primeira Infância. Mapeamento da Ação Finalística Evitando Acidentes na Primeira Infância. Fortaleza- CE, 2014. Disponível em:

$<$ http://primeirainfancia.org.br/wpcontent/uploads/2015/01/RELATORIO-DEMAPEAMENTO-EVITANDO-ACIDENTES-versao-4solteiras.pdf>. Acesso em: 22 fev. 2019.

BRASIL, Ministério da Saúde; Departamento de Atenção Básica; Coordenação-Geral de Alimentação e Nutrição Guia alimentar para crianças menores de 2 anos - Brasília, junho/julho de 2018.

Brasil Ministério da Saúde. Secretaria de Vigilância em Saúde. Secretaria de Atenção à Saúde. Política nacional de promoção da saúde: 2006.

Disponívelem:<http://portal.saude.gov.br/portal/arquivos/pdf /Politica_nacional_\%20saude_n v.pdf $>$ sociais.Acessado em 09 de abril, 2019.

Brasil MS. Saúde da Criança: Nutrição infantil, aleitamento materno complementar. Caderno de Atenção Básica [Internet]. 2009; n²3. Brasília - DF. 112 p.: Il. Disponível em:

http://bvsms.saude.gov.br/bvs/publicacoes/saude_crianca_nu tric. Acessado em 09 de abril de 2019.

CARVALHO, C.; FONSÊCA, P. C. C; PRIORE, S.E; FRANCESCHINI S. C. C; NOVAES, J. F.Consumo alimentar e adequação nutricional em crianças brasileiras: revisão sistemática. 2015 Disponível em: < 


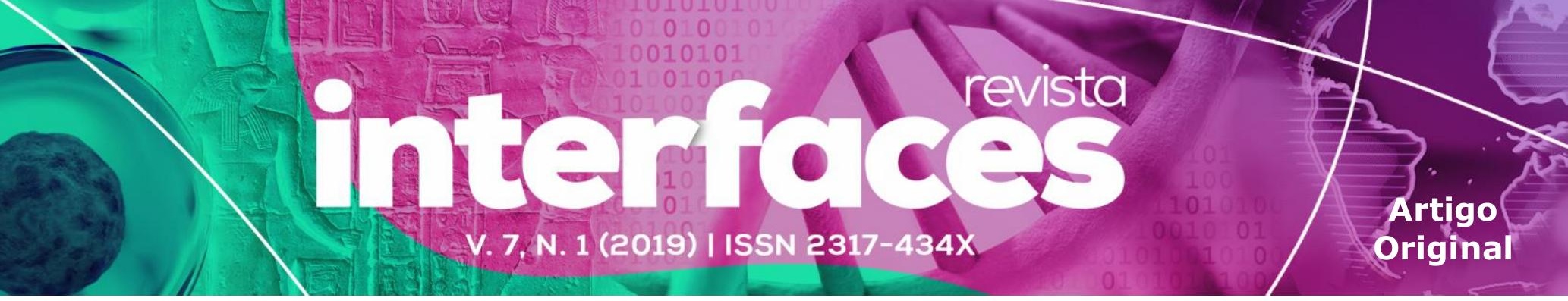

http://www.scielo.br/pdf/rpp/v33n2/pt_0103-0582-rpp33-0200211.pdf> Acesso em 22 Fev. 2019

DE LUNA BENICIO, A, et al. Cuidado à Criança Menor de um Ano: Perspectiva da Atuação do Enfermeiro na Puericultura. JournalofNursing UFPE/Revista de Enfermagem UFPE, 2016, 10.2. Disponível em: $<$ https://scholar.google.com.br/scholar?as_ylo=2015\&q=pre ven $\% \mathrm{C} 3 \% \mathrm{~A} 7 \% \mathrm{C} 3 \% \mathrm{~A} 30+\mathrm{de}+\mathrm{aci}$

dentes+menores+de+um+ano\&hl=pt-PT\&as_sdt=0,5>. Acesso em: 22 fev. 2019.

FILOCOMO, F, R, F et al . Perfil dos acidentes na infância e adolescência atendidos em um hospital público. Acta paul. enferm., São Paulo, v. 30, n. 3, p. 287-294, May 2017. Disponível em: <http://www.scielo.br/scielo.php?script=sci_arttext\&pid=S0 $10321002017000300287 \& \operatorname{lng}=\mathrm{en} \& \mathrm{nrm}=\mathrm{iso}>$. Acesso em: 22 fev.2019.

FROTA,M. A; BEZERRA, J. A; FÉRRER, M. L. S; MARTINS, M. C; SILVEIRA, V.G.

Percepção materna em relação ao cuidado e desenvolvimento infantil. RBPS, Fortaleza,

24(3):245-250, jul/set., 2011.Disponivel em: < https://periodicos.unifor.br/RBPS/article/view/2078> Acesso em 21 de fev. 2019.

CAMPOS, A.M.S; et al - Prática de aleitamento materno exclusivo informado pela mãe oferta de líquidos aos seus filhos. Rev. Latino-Am. Enfermagem mar.-abr. 2015;23(2):283 Disponível em www.scielo.br/pdf/rlae/v23n2/pt_0104-1169-rlae-23-0200283.pdf.

CRISTINA, M.G; ELSA, R.J - Recomendações para alimentação complementar da criança em aleitamento materno - Jornal de Pediatria Vol. 80, No5(supl), 2004. Disponívelem:

http://www.scielo.br/pdf/jped/v80n5s0/v80n5s0a04.

DIAS, M.C.A.P.; et al - Recomendações para alimentação complementar de crianças menores de dois anos: nutrição. Revista de Nutrição Vol.23 no. 3 Campinas maio/julho 2010. Disponivel em http://www.scielo.br/scielo.php?Script=script=SCarttex8pid=51415527320000300015

VASCONCELOS, et al. Puericultura: percepção de mães atendidas em unidade básica de saúde em sobral, ceará, Brasil. Rev .Nurs UFPE. 2010. 4(3):1492-497. Disponível em: http://bases.bireme.br/cgibin/wxislind.exe/iah/online/?IsisScr $\mathrm{ipt}=\mathrm{iah} / \mathrm{ia}$ h. $x$ is $\&$ src $=$ google $\&$ base $=$ BDENF $\&$ lang $=p \& n e x t$ Action $=$ lnk \&exprSearch=20364\&indexSearc h=ID. Acessado em: $23 \mathrm{de}$ março de 2019.

VIEIRA, et al. Puericultura na Atenção Primaria á Saúde: Atuação do Enfermeiro.

CogitareEnferm. 2012. Jan 12];17(1) Disponível em: http://ojs.c3sl.ufpr.br/ojs2/index.php/cogita re/article/view/26384.

SILVA, R.; BRANDÃO, D. Os quatro elementos da avaliação. São Paulo: Instituto Fonte, 2003. Disponível em: http://www.aberta.senad.gov.br. Acessado em: 22 de abril de 2019

OLIVEIRA, Antonio Benedito Silva. Métodos e técnicas de pesquisa em contabilidade. São Paulo: Saraiva: 2003. 